TECHNICAL PEREORMANCE REPOR:

\author{
submitted to \\ Division of Materials Sciences \\ Office of Basic Energy Sciences \\ U.S. Department of Energy
}

DOE/ER/ $45262--T 3$

DE92 003753

by

David J. Sellmyer, University of Nebraska

Titie: Eundamental Magnetic Studies of Iron-Rare-Earth-Metalioid Alloys Grant Numbers: DE-FCO2-86ER 45262

Reporting Périod: June 19, 1988-June 18, 1989

\title{
I. Entroduction
}

This research is pocussed on the synthesis of new iron-rare-earth magnetic phases which may have significant technological properties. An important aim is to investigate new methods for producing these materials such as melt spinning and sputtering plus specisic heat treatments. Studies are made of the relationship between microstructure and properties such as coercivity, spontaneous magnetization, and anisotropy (magnitude and direction) in bulk and thin film samples. Our goal is to understand these reiatively complex materials on the basis of fundamental electronic structure, theory is of itinerant magnetism and localized $4 f$ electronic states, and the microstructural effects which control the extrinsic properties. To achieve this a broad range of experiments and calculations are performed.

The present joint grant to the University of Nebraska (NU) and Kansas State University (KSU) supports three graduate students, two at NU and one at KSU. Recent degrees obtained with support of the present grant include those of Michael Engelhardt (now at the University of Wisconsin Synchrotron Radiation (enter) and Eric Singleton (now in a ?h.J. progra at KSU). Other

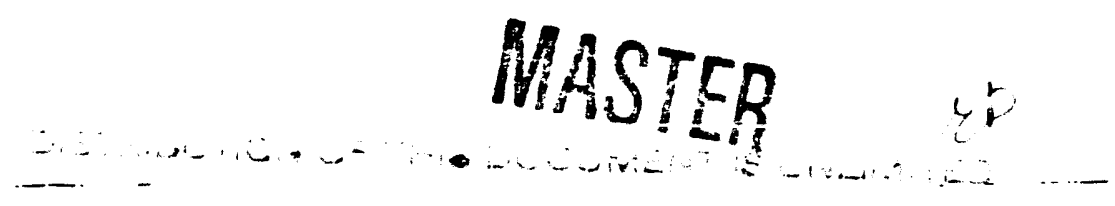


people including visiting scholars and professors have collaborated with us in this research and their names are included in the publication list at the end of this report. In particular we should mention professor S.S. JaswaI and M.A. Langell of NU, Dr. AI Arko of Argonne and now Los Alamos, and $Z . R$. Zhao and $W$. Gong who have now returned to the Institute of Physics in Beijing.

In the following we describe briefly some of our recent accomplishments, with emphasis on work performed in the last six months. Reference to specific publications in the attached list will be made with the notation [?1], for example.

II. Electronic Structure and Surface Reactivity of NdoEei 4 B and Related Compounds

In this work [P2] we have performed the first electronic structure measurements and self-consistent, spin-polarized band calculations on the $\mathrm{Nd}_{2} \mathrm{E} e_{i} \mathrm{~B}$ class of permanent-magnet materials. In addition to the Nd compound, measurements have been made on $\mathfrak{v}$ and $G d$ compounds to probe the efPects of the rare-earth electronic and magnetic structure. Photoelectron spectroscopy with 21.2 and $40.8 \mathrm{eV}$ photons was performed at NU and between 40 and $130 \mathrm{ev}$ at the Wisconsin Synchrotron, and the results were used to identify emission from the Ee 3d levels, which are exchange split by 2.1 $\mathrm{eV}$, and the quasi-iocalized $4 f$ levels. The $\mathrm{R}_{2} \mathrm{Fe}_{1} \mathrm{~B}$ compounds are shown to possess essentially identical electronic structures except for the 4 if Ievels associated with the rare-earth $(R)$ ions. Photoemission in the paramagnetic state shows a density-of-states essentially identical to that the Perromagnetic state; this gives strong evidence for considerable magretic short range order above $t_{c}$ for this class of compounds, as in the iluctuating-jand model of itinerant magnetism. The self-consistent LMTO calculations showed excelient agreement with the measured site-dependent Ee 
magnetic moments, and very small net charge transfers on the atomic sites. This latter conclusion will impinge on future attempts to calculate crystal Fields and anisotropy parameters in this class of materials.

Most recently, the work has been extended to the $R_{2} \mathrm{Co}_{14} \mathrm{~B}$ compounds [P6]. Here, the spin-polarized density-of-states for $Y_{2} \mathrm{CO}_{1} 4 \mathrm{~B}$ looks similar to that for pure Co, with an exchange splitting of about $1.3 \mathrm{ev.} \mathrm{Again} \mathrm{the}$ site-dependent moments were determined and lead to a total moment per formula unit of $18.3 \mathrm{HB}$ in comparison with the experimental value of $19.44 \mathrm{H}$. Eor the co sites the charge transfers were all less than about 0.4 electrons.

The $R_{2} F e_{1} B$ alloys with $R=Y$, Nd, and Gd were studied by the surface sensitive techniques of XPS and Auger electron spectroscopy (AES). It was found that heating to $350^{\circ} \mathrm{C}$ in $\mathrm{H}_{2}$ or $\mathrm{Co}$ removes surface oxygen, presumably through the formation and subsequent desorption of $\mathrm{H}_{2} \mathrm{O}$ and $\mathrm{CO}_{2}$, respectively. Clear evidence for surface segregation of $B$ and $N d$ was obtained at high temperatures, after sureace cleaning by Ar ion bombardment. The depth of oxidation of the compounds was studied by AES Ar sputtering, and differences were noted among the various rare earth compounds.

In general, the above research is encouraging because it has shown that state-of-the-art experimental and theoretical methods are, in fact, able to produce considerable insight into the fundamental electronic and magnetic structures of rather complex rare-earth transition-metal compounds.

\section{Study of New Rare-Earth Transition-Metal Phases}

The search for novel permanent magnet materials recently has focussed on ternary alloys containing iron to provide a high $M_{S}$, a light rare earth to provide significant anisotropy and ferromagnetic coupling with Ee, and a third element, either a metalloid or another transition metal, to provide an anisotropic crystal struczure which might provide uniaxiai anisotropy. 
One group of alloys that we have investigated recently is based on the ThMn $n_{12}$-type struture. The magnetic and structural properties of melt-spun $R_{8} E=84 T i 8$ with $\Omega=N d$, Sm, Dy, Gd and $R_{8}(E e, C 0) 76[V(M O)]_{16}$, with $R=N d$, Sm are being studied with $x$-ray diffraction, transmission electron microscopy and magnetic measurements. The tetragonal ThMn $n_{12}$-type structure is found in all alloys after annealing at around $700^{\circ} \mathrm{C}$. The Curie temperature $\left(T_{C}\right)$ of the as-spun samples is in the range of $40-100^{\circ} \mathrm{C}$. Crystallized Sm8 (Fe $1-x$ Cox)84T:8 samples with the $1: 12$ structure have $\equiv T_{C}$ around $250^{\circ} \mathrm{C}$ for $\mathrm{x}=0$, reaching the value of $660^{\circ} \mathrm{C}$ for $\mathrm{x}=0.5$ and then decreasing again to $490^{\circ} \mathrm{C}$ for $x=1$. The Curie temperatures of $1: 12$ prases in crystallized ribbons were found to be consistently lower than those obtained in as-cast alloys. The difference could not be explained simply by a composition variation in the ribbons. EDAX studies did not show significant differences in composition betweent he as-cast and melt-spun samples. However, with EDAX the true composition is not known on the microscopic level, since the EDAX signal comes from an area of about $1000 \AA$ and if some $\alpha-5 e$ precipitates are present in this area the composition determined will not be accurate. Another explanation for the lower $I_{c}$ could be a difference in site occupation in the $1: 12$ phase between the as-cast and melt-spun samples. Mössbauer studies are need to clarify this issue. AC susceptibility studies on Cosubstituted samoles show magnetic transitions in the temperature range $100-200 k$.

The highest value of coercivity obtained in samples annealed at around $100^{\circ} \mathrm{C}$ is $2 \mathrm{kDe}$ for a Sm-Ee-Ti sample. The coercivity is found to be strongiy dependent on the heat treatment. However, the coercivities are found to increase substantially $\left(\mathrm{H}_{\mathrm{C}}-7.7 \mathrm{kOe}\right.$; when a small amount of $\mathrm{B}$ is added into the sample and the ribbons are crystailized at nigher temperatures $\left(750-1000^{\circ} \mathrm{C}\right)$. The crystallization temperatures of the $1: 12$ alloys are in the range of $550-580^{\circ} \mathrm{C}$, abcut $200^{\circ} \mathrm{C}$ tigner than those obtained in 
$\mathrm{Nd}-\mathrm{Fe}-\mathrm{B}$ alloys. The $\mathrm{Nd}-\mathrm{Fe}-\mathrm{B}$ samples had to be annealed at temperatures $\left(700^{\circ} \mathrm{C}\right)$ much higher than the crystallization temperature for optimum magnetic hardening. This is because the grains of the anisotropic phase $(1: 12$ and $2: 14: 1$ ) must have the right size for maximum coercivity. The addition of $B$ into the $\mathrm{Sm}(\mathrm{Fe}, \mathrm{T})_{12}$ alloys not only improves the mechanical properties of the ribbon but also leads to crystallized microstructure with a smaller amount of $\alpha-F e$. The presence of $\alpha-F e$ may be critical in limiting the coercivities near $8 \mathrm{kOe}$. Since the anisotropy field of these compounds is even higher than that for $\mathrm{Nd}-\mathrm{E}-\mathrm{B}$ alloys, the coercivities are expected to increase even further. Several ways are being used to minimize the amount of a-Fe in the crystallized samples. Also, studies are now underway to see whether the hard magnetic properties can be produced in sintered magnets with chemical composition around those giving the good properties in ribbons since the $1: 12$ phase can easily be produced in bulk materials.

Further studies are also underway to determine the role of $B$ in improving the hard magnetic properties of melt-spun alloys. Current studies are underway to understand the origin of the coercivities by correlating the magnetic properties with the microstructure and magnetic domain structure. The improved coercivities and the high magnetization and magnetocrystalline anisotropy of these materials makes them attractive for further studies as possible candidates for permanent magnet development.

A second group of recent studies in the area of new phases concerns work on RE-TM alloys containing small amounts of oxygen. Recently we have obtained high coercivities in as-cast $\mathrm{Nd}(\mathrm{Pr})$-rich alloys with RE coropositions greater than 73 at. percent. The large $H_{C}$ values are attributed to the presence of a highly anisotropic phase with a Curie temperature around $250^{\circ} \mathrm{C}$. This phase is also present as a minority phase in alloys with compositions based on $\mathrm{Nd}_{73} \mathrm{Fe}_{27}$ and $\mathrm{Nd}_{50} \mathrm{Fe}_{50}$, but the coercivity in these latter alloys is negligible. The crystal structure of this phase is being 
studied at present. Mössbauer studies showed the presence of at least four inequivalent $F e$ sites with moments ranging from 1.7 to $2.5 \mu_{B}[? 10]$. This phase is believed to be a ternary compound stabilized by oxygen. SEM data show the phase to be present in the form of small spherical or elongated grains with an approximate size of 5um. EDAX studies indicate the Fe:Nd ratio to be about $3: 1$. We believe that the large $\mathrm{H}_{\mathrm{C}}$ values can be explained by the classical model of single domain particles in wich the fine Nd-Fe-O grains are distributed in a nonmagnetic Nd matrix.

A similar phase also is present in melt-soun ribbons. Crystallized $\mathrm{Nd}_{50} \mathrm{~F} e_{50}$ samples show high coercivities at room temperature. In the past, Croat has attributed this high coercivity to an unknown metastable phase. we believe that this phase also is oxygen stabilized Nd-Fe-O but its Curie temperature is slightly lower $\left(235^{\circ} \mathrm{C}\right)$ than the $\mathrm{Nd}-\mathrm{E} e-0$ phase in the as-cast samples $\left(260^{\circ} \mathrm{C}\right)$.

It has been suggested by Stadelmeier that there are two $\mathrm{Nd-Fe-O}$ phases which are ferromagnetic and magnetically hard. We are presently trying to grow single phase samples (by sputtering and aerosolization) in order to examine the intrinsic properties of the new phases, including crystal structure, magnetic moment, anisotropy, etc., and to determine whether they are good candidates for permanent magnet development.

\section{Souttered $N d_{2} E_{1} 4$ B Films and Multilayers}

We have been studying the production and properties of Co-doped sputtered thin films of the $\mathrm{Nd}_{2} \mathrm{~F} e_{14} \mathrm{~B}$ permanent magnet material. The purpose of this work is to determine how sputtering parameters and Co-doping affect the microstructure and resulting magnetic properties such as coercivity, Curie temperature, and magnetic domain structure. Large coercive fields $(\geq 10 \mathrm{kOe})$ have been produced in thin sputtered films of $\mathrm{Nd}_{2}\left(\Sigma e_{0} .9 \mathrm{CO} .1\right)_{14} \mathrm{~B}$, hereafter denoted as NE3. The films were either deposited at room tempera- 
ture and heat treated or deposited onto high-temperature substrates (to $\left.-730^{\circ} \mathrm{C}\right)$. Transmission electron microscopy was used to study the microstructure which consisted of very fine (100 - $500 \AA)$ crystallites. Correlations were observed between sputtering and growth parameters, microstructure, and magnetic properties. In particular, Lorentz microscopy studies showed domain patterns characteristic of either in-plane or perpendicular magnetization in appropriately prepared samples. These data are consistent with the anisotropies observed in magnetization measurements, and also with textured microstructure as observed in $x$-ray and electron diffraction. These results are described fully in recent publications [P3, P7].

In producing very thin films (1000 $\AA$ ) of the $2: 14: 1$ phase it was necessary to undercoat and overcoat the films with thin layers of Au $(-200 \AA)$. This prevented the oxidation of the Nd. In addition we have found that there are significant chemical interactions of the 2:14:1 phase with the mica substrate so that appreciable $\mathrm{NdO}$ is found in the film. This can be eliminated either by first depositing a 500 \& buffer layer of $E e$ on the mica or by using a Ta substrate. In the case of films deposited onto $22^{\circ} \mathrm{C}$ substrates and then annealed at $600^{\circ} \mathrm{C}$ to crystallize the $2: 14: 1$ phase, some fraction of tie film consists of the rhombohedral $\mathrm{Nd}_{2} \vec{F} e_{17}(2: 17)$ phase. Depending on other aspects of the microstructure (grain size, disorder, etc.), such secondary phases can either help or hinder the growth of high coercivity films.

In very recent work we have been emphasizing the control of microstructure by multilayering NFB with other metals such as $A g, F e$, and $T a$ [P7]. A large number of fllms have been grown with NFB layer thicknesses ranging from about $50-500 \AA$, and about $5-50 \AA$ for the other metal. In certain cases, diffraction studies have shown compound formation at the interfaces (e.8., $\mathrm{NdAg}$ and $\mathrm{Fe}_{2} \mathrm{Ta}$ ). Some of the general conclusions thus far are that the magnitude of the magnetization, the direction of the uniaxial aniso- 
tropy (perpendicular or in-plane) and the coercivity can be easily controlled by the individual layer thicknesses. In the case of NFB/Ta multilayers, coercivities up to about $23 \mathrm{kOe}$ have been obtained and the temperature dependence of $\mathrm{H}_{C}$ is similar to that of rapidly quenched and heat treated samples with a fine-particle microstructure. The preliminary results are consistent with a pinning controlled magnetization reversal mechanism. Further studies involving correlation of the layered microstructure with the properties are underway.

\section{Publications and Presentations}

\section{Publications:}

1. G.C. Hadjipanayis, S.H. Aly and S.F. Cheng, HARD MAGNETIC PROPERTIES OF R-Fe-Ti ALlOYS, Appl. Phys. Lett. 191,2048 (1987).

2. D.J. Sellmyer, M.A. Engelhardt, S.S. Jaswal and A.J. Arko, ELECTRONIC STRUCTURE AND MAGNETISM OF $\mathrm{Nd}_{2} \mathrm{Fe}_{1} 4 \mathrm{~B}$ AND RELATED COMPOUNDS, Phys. Rev. Letters 60,2077 (1988).

3. J. Strzeszewski, A. Nazareth, G.C. Hadjipanayis, K.D. Aylesworth, Z.R. Zhao and D.J. Sellmyer, MICROSTRUCTURE STUDIES IN $\mathrm{Nd}_{2}\left(F e_{0.9} C_{00} .1\right) 14 \mathrm{~B}$ THIN FILMS, Mat. Sci. Engr. 99, 153 (1988).

4. Z.R. Zhao, Y.G. Ren, K.D. Aylesworth, D.J. Sellmyer, E. Singleton, J. Strzeszewski and G.C. Hadjipanayis, MAGNETIC PROPERTIES OF RAPIDLY QUENCHED AND ANNEALED Fe 10 RTI AND RELATED PHASES, J. Appl. Phys. 63, 3699 (1988).

5. S.H. Aly, G.C. Hadjipanay1s, Z.R. Zhao and D.J. Sellmyer, MAGNETIC PROPERTIES OF RARE-EARTH TRANSITION-METAL BORIDES, J. APPI. PhyS. 63, 3704 (1988). 
6. S.S. Jaswal, M.A. Langell, Y.G. Ren, M.A. Engelhardt and D.J. SEIImyer, ELECTRONIC STRUCTURE AND SURFACE REACTIVITY OF $\mathrm{Nd}_{2} \mathrm{Fe}_{14} \mathrm{~B}$ AND RELATED COMPOUNDS, J. Appl. Phys. 64, 5577 (1988).

7. K.D. Aylesworth, Z.R. Zhao, D.J. Sellmyer and G.C. Hadjipanayis, MAGNETIC AND STRUCTURAL PROPERTIES OF $\mathrm{Nd}_{2} \mathrm{Fe}_{14} \mathrm{~B}$ PERMANENT-MAGNET FILMS AND MULTILAYERS WITH Fe AND Ag, J. Appl. Phys. 64, 5742 (1988).

8. E.W. Singleton, J. Strzeszewski, G.C. Hadjipanayis and D.J. Sellmyer, MAGNETIC AND STRUCTURAL PROPERTIES OF MELT-SPUN RARE-EARTH TRANSITION METAL INTERMETALLICS WITH ThMn 12 STRUCTURE, J. Appl. Phys. 64, 5717 $(1988)$.

9. A. Tsoukatos, J. Strzeszewski and G.C. Hadjipanayis, HIGH COERCIVITIES IN AS-CAST Nd-Fe AND Nd-Fe-Ti ALlOYS, J. Appl. Phys. 64, 5971 (1988).

10. G.C. Hadjipanayis, A. Tsoukatos, J. Strzeszewsi, G.J. Long and A. Pringle, A NEW HARD MAGNETIC PHASE IN BINARY Nd-Fe ALLOYS, J. Magm. and Magnet. Matis., (in press).

11. G.C. Hadjipanayis, S. Nafis and W. Gong, A STUDY OF THE HARD MAGNETIC PROPERTIES IN DIFEERENT HARD MAGNETIC MATERIALS, J. de Physique, (in press).

12. K.D. Aylesworth, Z.R. Zhao, D.J. Selimyer and G.C. Hadjipanayis, GROWTH AND CONTROL OF THE MICROSTRUCTURE AND MAGNETIC PROPERTIES OF SPUTTERED $\mathrm{Nd}_{2} \mathrm{Fe}_{14} \mathrm{~B}$ FILMS AND MULTILAYERS, in preparation.

\section{Papers Presented at Meetings:}

1. D.J. Sellmyer, M.A. Engelhardt, A.J. Arko, and W.Y. Ching, PHOTOEMISSION AND ELECTRONIC STRUCTURE OF $\mathrm{Fe}_{1} 4 \mathrm{Nd}_{2} \mathrm{~B}$, Bull. Am. Phys. SOC. $\underline{32}$, 415 (1987), March A.P.S. Meeting, New York. 
2. Z.R. Zhao, D.J. Sellmyer, Z.S. Shan, and G.C. Hadjipanay is, MAGNETIC PROPERTIES, ANISOTROPY, AND MICROSTRUCTURE OF SPUTTERED (FECO)NAB THIN FILMS, Bull. Am. Fhys. Soc. 32, 803 (1987), A.P.S. Meeting, New York.

3. S.H. Aly, G.C. Hadjipanayis, Z.R. Zhao, and D.J. Sellmyer, MAGNETIC PROPERTIES OF RARE EARTH-TRANSITION METAL BORIDES, CONf. On Magnetism and Magnetic Materials, Chicago, (1987).

4. Z.R. Zhao, Y.G. Ren, D.J. Sellmyer, S.H. Aly, and G.C. Hadjipanayis, MAGNETIC PROPERTIES OE RAPIDLY QUENCHED AND CRYSTALLIZED Fe 10 RTI ALLOYS, Conf. on Magnetism and Magnetic Materials, Chicago (1987).

5. G.C. Hadjipanayis, D.J. Sellmyer, Z.R. Zhao and Z.S. Shan, MICROSTRUCTURE AND MAGNETIC PROPERTIES OF SPUTTERED (FeCO)NAB FILMS, Intermag, Tokyo (1987).

6. J. Strzeszewski, G.C. Hadjipanayis, K. Aylesworth and D.J. Sellmyer, MICROSTRUCTURE STUDIES IN $\mathrm{Nd}_{2}\left(\mathrm{~F} \mathrm{E}_{0.9} \mathrm{~g}^{\mathrm{C}} 00.1\right)_{14} \mathrm{~B}$ THIN FILMS, RQ6, Montreal (1987).

7. Z.R. Zhao, K.D. Aylesworth, D.J. Sellmyer and G.C. Hadjipanayis, MAGNETIC PROPERTIES OF NANOSTRUCTURED NAFeCOB/AY MULTILAYERS, BUIl. Am. Phys. Soc. 33 , 392 (1988), March A.P.S. Meeting, New Orleans.

8. M.A. Engelhardt, S.S. Jaswal and D.J. Sellmyer, ELECTRON STRUCTURE AND PHOTOEMISSION OF $R_{2} F e_{14} B(R=Y, N d, G d)$, Bull. Am. Phys. Soc. $\underline{33}, 579$ (1988), March A.P.S. Meeting, New Orleans.

9. E.W. Singleton, J. Strzeszewski, G.C. Hadjipanayis and D.J. Sellmyer, MAGNETIC PROPERTIES OF RARE-EARTH TRANSITION-METAL INTERMETALLICS WITH ThMn 12 STRUCTURE, Bull. Am. Phys. Soc. 33,812 (1988), March A.P.S. Meeting, New Orleans.

10. S.S. Jaswal, M.A. Engelhardt, M.A. Langell and D.J. Sellmyer, ELECTRONICS STRUCTURE AND SURFACE REACTIVITY OF R $\mathrm{Fe}_{14} \mathrm{~B}$ AND RELATED COMPOUNDS, M3I Conf., Vancouver, Canada, (1988). 
11. E.W. Singleton, J. Strzeszewsk1, G.C. Hadjipanayis and D.J. Sellmyer, MAGNETIC AND STRUCTURAL PROPERTIES OF MELT-SPUN RARE-EARTH TRANSITIONMETAL INTERMETALLICS WITH ThMn 12 STRUCTURE, M3I COnf., Vancouver, Canada, (1988).

12. K.D. Aylesworth, Z.R. Zhao, D.J. Sellmyer and G.C. Hadjipanayis, MAGNETIC AND STRUCTURAL PROPERTIES OF $\mathrm{Nd}_{2} \mathrm{~F} e_{14} \mathrm{~B}$ PERMANENT-MAGNET FILMS AND MULTILAYERS WITH Fe AND Ag, M3I Conf. Vancouver, Canada, (1988). 

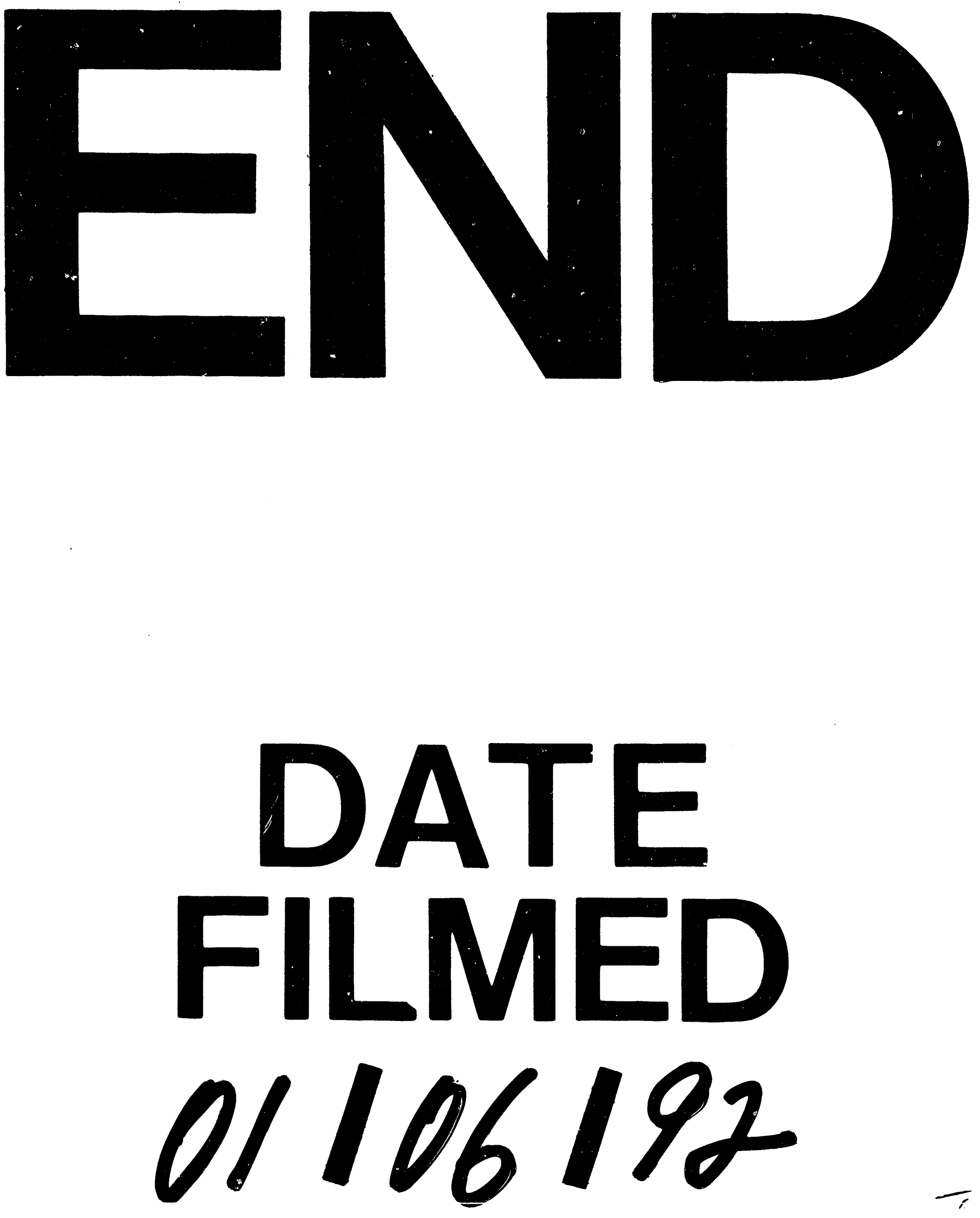

$=1$ 